\title{
A Dual Reflector Antenna for Point-to-Point System Applications
}

\author{
M. OlszeWskA* AND W. GWAREK \\ Institute of Radioelectronics, Warsaw University of Technology \\ Nowowiejska 15/19, 00-665 Warsaw, Poland
}

\begin{abstract}
In this paper design and realization of a dual reflector antenna for receiving internet signal in the point-to-point system is presented. Three different configurations of dual reflector antenna have been considered to obtain the antenna operating in 5.2-5.8 GHz band and having small dimensions. The results of computer simulations and measurements are shown. The design was based on electromagnetic simulations using QW-V2D package (an axisymmetrical version of finite-difference time-domain software). In measurements the method with a reference antenna was used. Additional discussion about using the main reflector of smaller diameter and decreasing spillover radiation was performed.
\end{abstract}

PACS: $41.20 .-\mathrm{q}$

\section{Introduction}

Dual reflector antennas are frequently applied for earth stations of satellite communication systems and in radioastronomy [1-3]. Such a solution has one important advantage: the receiver (or down-converter) can be placed behind the main reflector. This way we avoid the shadow introduced by the receiver and its mechanical support as well as the necessity for a relatively long (and lossy) line to transmit the signal out of the reflector interior. Those advantages are clear in the above mentioned applications, where the typical sizes of the main reflectors are measured in hundreds of wavelengths. The sub-reflectors which are supposed to be of an order of magnitude smaller have typically a size of a few tens of wavelengths and can be treated by the quasi-optical approach to the reflector theory.

The situation changes when we want to apply a dual reflector construction to a relatively small antenna of about 20 wavelengths in size and directivity of about $35 \mathrm{~dB}$. Such antennas are often needed for point-to-point systems. One of their popular applications is the internet connection, where fiber or cable transmission is impossible or too expensive. Yet it is not quite clear if we can construct an effective dual reflector antenna of a small size (with sub-reflector not bigger than two or three wavelengths).

In this paper we discuss whether a dual reflector antenna of diameter between 0.4 and $1.2 \mathrm{~m}$ could be an alternative for a front feed parabolic antenna of the same diameter.

* corresponding author; e-mail: M.0lszewska@ire.pw.edu.pl
The main effort was directed towards the design of a small sub-reflector of about $10 \mathrm{~cm}$ in diameter optimized for operation in the $5.2-5.8 \mathrm{GHz}$ band. The reflector is supposed to be suspended on a plastic tube connecting it with the feeding waveguide extruding from a main reflector.

Our target was to obtain the directivity of about $34 \mathrm{~dB}$ with the main reflector of $1.1 \mathrm{~m}$ or $32.25 \mathrm{~dB}$ with the main reflector of $0.9 \mathrm{~m}$. The sidelobes should be at about $-20 \mathrm{~dB}$. Such parameters would make our solution competitive with the available front-feed antennas.

Using the electromagnetic simulator QW-V2D [4] we have verified several concepts of sub-reflector constructions. The main reflector of $1.1 \mathrm{~m}$ was used as a reference. The best of the obtained designs was chosen for manufacturing of an antenna prototype, which was then experimentally verified.

The highlights of the design were presented in [5], and have been extended in this paper.

\section{Dual reflector antennas}

\subsection{The Cassegrain antenna}

Classical Cassegrain antenna consists of the parabolic main reflector and hyperbolic sub-reflector. To ensure correct operation of the Cassegrain antenna, focal points of both reflectors should overlap. We started our investigation with an effort to design such an antenna. It was quickly found that a sub-reflector diameter of $0.1 \mathrm{~m}$ is not realistic. The use of a small sub-reflector increased leakage of the electromagnetic energy over the hyperbolic reflector. On the other hand, increasing the diameter of the sub-reflector increased aperture blockage. Finally we eased the requirements for the sub-reflector size to $0.2 \mathrm{~m}$ 
(Fig. 1). Under such conditions we obtained the directivity equal to $32 \mathrm{~dB}$. Sidelobe level was equal to $-10 \mathrm{~dB}$ and return loss equal to $4 \mathrm{~dB}$. The requirements for directivity, attenuation of sidelobes, and diameter of the sub-reflector have not been accomplished.

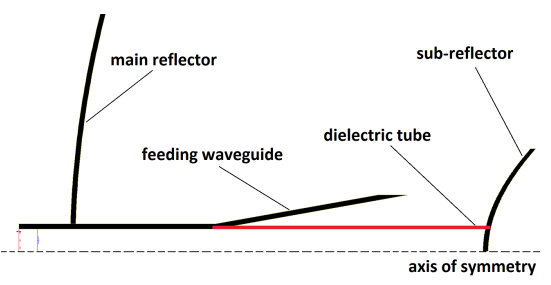

Fig. 1. Fragment of the designed Cassegrain antenna including the feeding waveguide and the sub-reflector (half of long section).

\subsection{The hat-fed reflector antenna}

There are some configurations of the double reflector antennas, which can be found in the literature, for example the antenna with flat sub-reflector in [6]. That type of the dual reflector antenna is known as the hat-fed reflector antenna and it provides a relatively high directivity and low sidelobes. Following that line we designed the construction shown in Fig. 2. The number and dimensions of corrugations were optimized for high directivity and low sidelobes. We obtained the directivity of $33.7 \mathrm{~dB}$, sidelobe level equal to $-20 \mathrm{~dB}$, and return loss $4 \mathrm{~dB}$. Still the design was not satisfactory since the matching was poor and the sub-reflector was relatively big and complicated to manufacture.

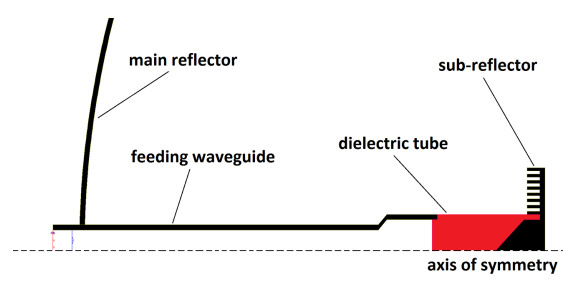

Fig. 2. Fragment of the designed hat-fed reflector antenna including the feeding waveguide and the sub-reflector (half of long section).

\subsection{The dual reflector antenna with modified flat sub-reflector}

To eliminate the weaknesses of the previous design we introduced an additional impedance transformer and tried to optimize the reflector to make it smaller and simpler (also less expensive to manufacture). The QW-V2D model of the obtained dual-reflector antenna is shown in Fig. 3a. Details of the sub-reflector are presented in Fig. 3b and its photo is in Fig. 4. The sub-reflector has only one corrugation. Diameter of the flat reflector is $0.1 \mathrm{~m}$ and length of the matching transformer is $0.054 \mathrm{~m}$.
The results of simulations have shown that the double reflector antenna of Fig. 3 is the most promising and we will concentrate on it in our further investigation.

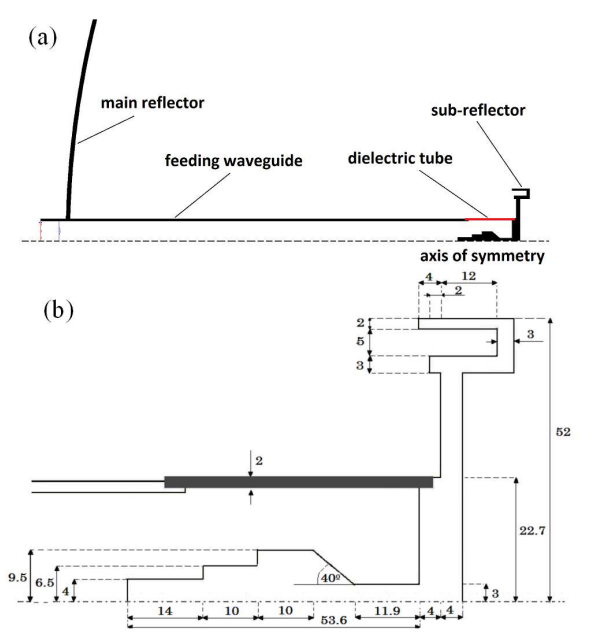

Fig. 3. Fragment of the designed dual reflector antenna with modified flat sub-reflector (a), detailed view of modified flat sub-reflector (b) (half of long section).

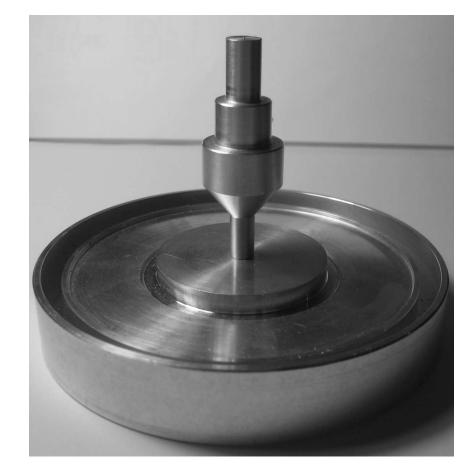

Fig. 4. Realization of modified flat sub-reflector.

\section{Simulations and measurements}

The simulations and optimization of the double reflector antenna have been performed in QuickWave-V2D, which is an axisymmetrical version of FDTD software [7]. The main purpose of the optimization was to obtain directivity of minimum $34 \mathrm{~dB}$ (with $1.1 \mathrm{~m}$ main reflector), $-20 \mathrm{~dB}$ of sidelobe level and return loss in the operation band of minimum $15 \mathrm{~dB}$.

Radiation $E$-pattern and reflection coefficient at the waveguide input obtained from simulations, performed for the antenna of Fig. 3 are shown in Figs. 5 and 6 . The simulations were performed for three frequencies from the operating band: lower $-5.2 \mathrm{GHz}$, middle - 5.5 GHz, and upper - 5.8 GHz. For all the considered frequencies the directivity exceeded $34 \mathrm{~dB}$. The level of close sidelobes was equal to $-23.5 \mathrm{~dB},-20.4 \mathrm{~dB}$, 


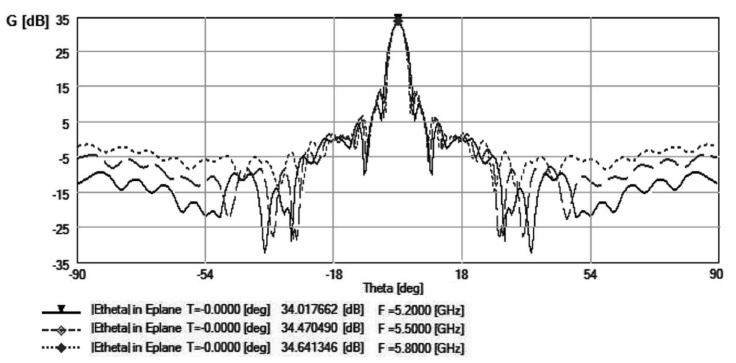

Fig. 5. Directive gain versus angle for the dual reflector antenna of Fig. 3, calculated by QW-V2D.

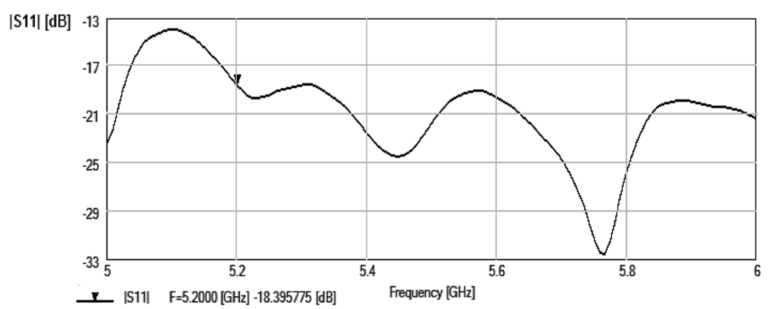

Fig. 6. Value of waveguide (Fig. 3) $\left|S_{11}\right|$ versus frequency, calculated by QW-V2D.

and $-20 \mathrm{~dB}$ for $5.2 \mathrm{GHz}, 5.5 \mathrm{GHz}$, and $5.8 \mathrm{GHz}$, respectively. The spillover radiation attenuation was equal to $46.2 \mathrm{~dB}$ for $5.2 \mathrm{GHz}, 39.4 \mathrm{~dB}$ for $5.5 \mathrm{GHz}$, and $36 \mathrm{~dB}$ for $5.8 \mathrm{GHz}$. The impedance transformer improved the matching. The $\left|S_{11}\right|$ decreased significantly, and was lower than $-18.4 \mathrm{~dB}$ in the entire operating band.

In the measurements of the antenna prototype we applied a reflector of the diameter $0.9 \mathrm{~m}$ (which is supposed to assure the directivity about $1.73 \mathrm{~dB}$ lower than the reflector of the diameter $1.1 \mathrm{~m}$ ). In the measurements we have applied a method with two different antennas, the designed one and the reference antenna with the known gain. The results of the measurements are shown in Fig. 7.

Some additional simulations were required since in the antenna prototype the main reflector of different diameter was applied. Results of the simulations and the measurements are summarized in Table I. Some doubts concerning the differences in $\left|S_{11}\right|$ values obtained from simulations and in measurements can appear.

To excite the antenna properly the coaxial line to cylindrical waveguide transition has been designed. In this design the " $\mathrm{N}$ " type junction was used. Unavailability of the calibration kit for the "N" type junctions caused the necessity of using in the reflection coefficient measurements the "SMA" type junction calibration kit. In the measurements the "SMA"-"N" transition was crucial. The most probable reason for the mentioned differences in $\left|S_{11}\right|$ values are significant reflections in the "SMA"-"N" transition.

TABLE I

Parameters of the dual reflector antenna with modified flat sub-reflector and main reflector of diameter $0.9 \mathrm{~m}$ obtained in simulations and measurements.

\begin{tabular}{|c|c|c|c|c|c|c|}
\hline \multirow{3}{*}{ Parameter } & \multirow{2}{*}{\multicolumn{3}{|c|}{ Simulation }} & \multirow{2}{*}{\multicolumn{3}{|c|}{$\frac{\text { Measurement }}{\text { Vertical polarization }}$}} \\
\hline & & & & & & \\
\hline & $5.2 \mathrm{GHz}$ & $5.5 \mathrm{GHz}$ & $5.8 \mathrm{GHz}$ & $5.2 \mathrm{GHz}$ & $5.5 \mathrm{GHz}$ & $5.8 \mathrm{GHz}$ \\
\hline gain $[\mathrm{dB}]$ & 30.87 & 32.25 & 32.65 & 30.6 & 30.2 & 31.2 \\
\hline sidelobe level $[\mathrm{dB}]$ & -24.6 & -18.6 & -16.9 & -24.8 & -17.8 & -14.6 \\
\hline $90^{\circ}$ radiation attenuation $[\mathrm{dB}]$ & 37.3 & 33.4 & 33.3 & 39 & 37.5 & 35.4 \\
\hline backward radiation attenuation $[\mathrm{dB}]$ & 33.1 & 32.2 & 37.8 & 35 & 31.5 & 33 \\
\hline$\left|S_{11}\right|[\mathrm{dB}]$ & \multicolumn{3}{|l|}{$<-13$} & \multicolumn{3}{|l|}{$<-4.7$} \\
\hline
\end{tabular}

\section{The dual reflector antenna with main reflector of different diameter}

Due to small dimensions of the designed flat sub-reflector, simulations of the dual reflector antenna for different diameters of the main reflector were performed. The aim of those simulations was to verify whether the designed flat sub-reflector co-operating with the main reflector of diameter significantly smaller than $1.1 \mathrm{~m}$ could be considered as an alternative for commercially available antennas for receiving internet signal in point-to-point systems.
It was concluded that the dual reflector antenna with the chosen flat sub-reflector and the main reflector of diameter equal to $0.45 \mathrm{~m}$ or $0.5 \mathrm{~m}$ could be considered as an alternative for commonly used patch array antennas. The directivity of those antennas is around $23 \mathrm{~dB}$, sidelobe level over $-15 \mathrm{~dB}$, and dimensions in the range 0.3-0.4 m. The results of simulations obtained for these two configurations of the double reflector antenna are shown in Tables II and III. 
TABLE II

Parameters of the dual reflector antenna with the main reflector of diameter $0.45 \mathrm{~m}$.

\begin{tabular}{lll}
\hline \hline \multicolumn{2}{c|}{ Parameter } & \multicolumn{1}{c}{ Value } \\
\hline main reflector diameter & $0.45 \mathrm{~m}$ \\
$f / D$ ratio & 0.39 \\
Half angle of the main reflector & $65.2^{\circ}$ \\
directivity $5.2 \mathrm{GHz}$ & $25.9 \mathrm{~dB}$ \\
& $5.5 \mathrm{GHz}$ & $25.5 \mathrm{~dB}$ \\
& $5.8 \mathrm{GHz}$ & $27.2 \mathrm{~dB}$ \\
sidelobe level & $5.2 \mathrm{GHz}$ & $-25 \mathrm{~dB}$ \\
& $5.5 \mathrm{GHz}$ & $-15.8 \mathrm{~dB}$ \\
& $5.8 \mathrm{GHz}$ & $-18.2 \mathrm{~dB}$
\end{tabular}

TABLE III Parameters of the dual reflector antenna with the main reflector of diameter $0.5 \mathrm{~m}$.

\begin{tabular}{|c|c|c|}
\hline \multicolumn{2}{|c|}{ Parameter } & Value \\
\hline \multicolumn{2}{|c|}{ main reflector diameter } & $0.5 \mathrm{~m}$ \\
\hline \multicolumn{2}{|c|}{$f / D$ ratio } & 0.37 \\
\hline \multicolumn{2}{|c|}{ half angle of the main reflector } & $68.2^{\circ}$ \\
\hline \multirow[t]{3}{*}{ directivity } & $5.2 \mathrm{GHz}$ & $26.6 \mathrm{~dB}$ \\
\hline & $5.5 \mathrm{GHz}$ & $25.9 \mathrm{~dB}$ \\
\hline & $5.8 \mathrm{GHz}$ & $27.6 \mathrm{~dB}$ \\
\hline \multirow[t]{3}{*}{ sidelobe level } & $5.2 \mathrm{GHz}$ & $-23.8 \mathrm{~dB}$ \\
\hline & $5.5 \mathrm{GHz}$ & $-17.4 \mathrm{~dB}$ \\
\hline & $5.8 \mathrm{GHz}$ & $-19.5 \mathrm{~dB}$ \\
\hline
\end{tabular}

\section{Spillover radiation}

It was interesting to investigate whether there was a possibility to decrease the spillover radiation for the double reflector antenna, with the main reflector of diameter $1.1 \mathrm{~m}$ and the designed sub-reflector.

\subsection{Different $f / D$ ratios for the main reflector}

The first step was to check the influence of the main reflector $f / D$ ratio changes $(D=1.1 \mathrm{~m})$ on antenna parameters. The most interesting for us was the directivity, the attenuation of sidelobes and the spillover radiation. Several simulations for the double reflector antenna with the main reflector of diameter $1.1 \mathrm{~m}$ for different $f / D$ ratios have been performed, and the results have been shown in Table IV.

Both, the attenuation of sidelobes and spillover radiation for smaller $f / D$ had values similar to those obtained for the antenna from Fig. $3(f / D=0.41)$. It can be also observed that for very small $f / D$ ratio, equal to 0.25 the spillover radiation has decreased. The directivity has decreased with decreasing $f / D$ ratio, and for the lower frequency was almost $4 \mathrm{~dB}$ lower than for $f / D=0.41$.

According to the results presented in Table IV the spillover radiation cannot be decreased by introducing the main reflector with a smaller $f / D$ ratio, without decreasing other antenna parameters, especially the directivity.

\section{TABLE IV}

Parameters of the dual reflector antenna with the main reflector of diameter $1.1 \mathrm{~m}$ for different $f / D$ ratios.

\begin{tabular}{c|c|c|c}
\hline \hline$f / D$ & Directivity & Sidelobe level & Spillover attenuation \\
& $(5.2 \mathrm{GHz}, 5.5 \mathrm{GHz}, 5.8 \mathrm{GHz})$ & $(5.2 \mathrm{GHz}, 5.5 \mathrm{GHz}, 5.8 \mathrm{GHz})$ & $(5.2 \mathrm{GHz}, 5.5 \mathrm{GHz}, 5.8 \mathrm{GHz})$ \\
\hline 0.41 & $34 \mathrm{~dB}, 34.47 \mathrm{~dB}, 34.64 \mathrm{~dB}$ & $-23.5 \mathrm{~dB},-20.4 \mathrm{~dB},-20 \mathrm{~dB}$ & $46.2 \mathrm{~dB}, 39.4 \mathrm{~dB}, 36 \mathrm{~dB}$ \\
0.385 & $33.25 \mathrm{~dB}, 34.11 \mathrm{~dB}, 34.36 \mathrm{~dB}$ & $-33.2 \mathrm{~dB},-23 \mathrm{~dB},-22 \mathrm{~dB}$ & $43 \mathrm{~dB}, 38 \mathrm{~dB}, 34.5 \mathrm{~dB}$ \\
0.37 & $33.15 \mathrm{~dB}, 34.16 \mathrm{~dB}, 34.46 \mathrm{~dB}$ & $-26 \mathrm{~dB},-22 \mathrm{~dB},-23 \mathrm{~dB}$ & $41 \mathrm{~dB}, 35 \mathrm{~dB}, 34 \mathrm{~dB}$ \\
0.33 & $32.37 \mathrm{~dB}, 33.95 \mathrm{~dB}, 34 \mathrm{~dB}$ & $-24 \mathrm{~dB},-20 \mathrm{~dB},-22 \mathrm{~dB}$ & $41 \mathrm{~dB}, 36 \mathrm{~dB}, 36 \mathrm{~dB}$ \\
0.3 & $31.57 \mathrm{~dB}, 33.75 \mathrm{~dB}, 33.95 \mathrm{~dB}$ & $-26 \mathrm{~dB},-20 \mathrm{~dB},-20 \mathrm{~dB}$ & $41 \mathrm{~dB}, 38 \mathrm{~dB}, 38 \mathrm{~dB}$ \\
0.25 & $30.22 \mathrm{~dB}, 32.64 \mathrm{~dB}, 32.9 \mathrm{~dB}$ & $-23 \mathrm{~dB},-18 \mathrm{~dB},-22 \mathrm{~dB}$ & $45 \mathrm{~dB}, 44 \mathrm{~dB}, 45 \mathrm{~dB}$
\end{tabular}

\subsection{Introducing the metal flange}

In the second step the metal flange around the main reflector as in Fig. 8 was introduced. An example of the metal flange application can be found in [8]. Since the flange is placed at the reflector edge, it should decrease the spillover radiation. Several simulations for antenna configuration from Fig. 8 were performed. The aim was to investigate whether the spillover radiation can be decreased by introducing the metal flange and how it influences the other antenna parameters.

The flange used in simulations was $190.5 \mathrm{~mm}$ long and $3 \mathrm{~mm}$ thick. The results of simulations of the considered configuration of the antenna are presented in Table V. It was easily concluded that the spillover radiation can be decreased by introducing the metal flange.
The advantage of this design was a fact that no significant degradation of other antenna parameters can be observed. The value of $\left|S_{11}\right|$ was bigger than for the antenna from Fig. 3, but still the requirements have been satisfied.

\section{Conclusions}

Three configurations of the double reflector antenna were analyzed. The antenna with the modified flat sub-reflector was designed, manufactured, and measured. A good agreement between simulations and measurements was obtained.

Additional simulations for different diameters of the main reflector were performed. Due to a relatively small 


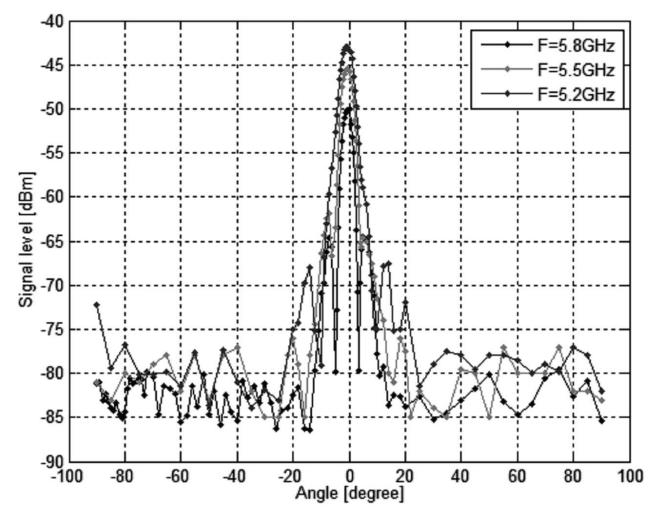

Fig. 7. Level of the signal received by manufactured antenna versus angle.

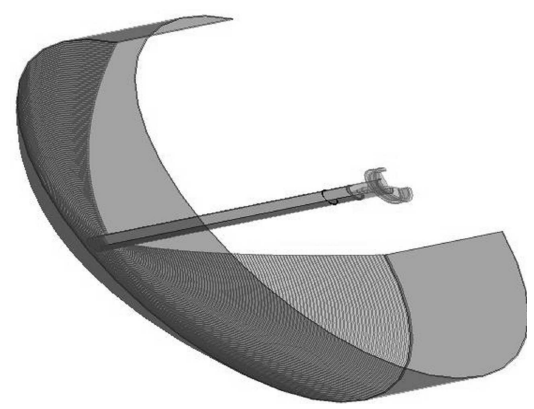

Fig. 8. The double reflector antenna from Fig. 3 with the metal flange $-3 \mathrm{D}$ view from $\mathrm{QW}-\mathrm{V} 2 \mathrm{D}$.

diameter of the designed flat sub-reflector, the double reflector antennas with smaller parabolic main reflector could be considered as an alternative for commercially available antennas for receiving internet signal in point-to-point systems.

Discussion concerning the decrease of the spillover radiation has been performed. It was concluded that introducing a metal flange at the edge of the main reflector is an effective way of decreasing the spillover radiation.
TABLE V

Parameters of the dual reflector antenna with metal flange (Fig. 8).

\begin{tabular}{ll|l}
\hline \hline \multicolumn{2}{c|}{ Parameter } & \multicolumn{1}{c}{ Value } \\
\hline directivity & $5.2 \mathrm{GHz}$ & $34 \mathrm{~dB}$ \\
& $5.5 \mathrm{GHz}$ & $34.47 \mathrm{~dB}$ \\
sidelobe level & $5.8 \mathrm{GHz}$ & $34.67 \mathrm{~dB}$ \\
& $5.2 \mathrm{GHz}$ & $-24.9 \mathrm{~dB}$ \\
& $5.5 \mathrm{GHz}$ & $-20.1 \mathrm{~dB}$ \\
spillover attenuation & $5.8 \mathrm{GHz}$ & $-20 \mathrm{~dB}$ \\
& $5.2 \mathrm{GHz}$ & $58 \mathrm{~dB}$ \\
& $5.5 \mathrm{GHz}$ & $43.1 \mathrm{~dB}$ \\
$\left|S_{11}\right|$ & $5.8 \mathrm{GHz}$ & $36.8 \mathrm{~dB}$ \\
& & $<-15.6 \mathrm{~dB}$
\end{tabular}

\section{References}

[1] C.A. Balanis, Antenna Theory. Analysis and Design, Wiley, New York 1997.

[2] P.-S. Kildal, Foundations of Antennas. A Unified Approach, Studentlitteratur, Lund 2000.

[3] Y.T. Lo, S.W. Lee, Antenna Handbook, Vol. III Antenna Applications, Chapman and Hall, New York 1993.

[4] www.qwed.com.pl .

[5] M. Olszewska, W. Gwarek, in: Proc. 18th Int. Conf. on Microwave, Radar and Wireless Communications MIKON-2010, Vilnius (Lithuania), 2010, p. 26.

[6] J. Hansen, A.A. Kishk, P.-S. Kildal, O. Dahlsjö, in: Antennas and Propagation Society Int. Symp., Newport Beach (CA), Vol. 2, 1995, p. 893.

[7] M. Celuch, W.K. Gwarek, IEEE Microwave Mag. 9, 150 (2008).

[8] H.W. Ehrenspeck, Proc. IEEE 53, 1138 (1965). 